\title{
Effects of sucrose concentrations on single-alternation performance in rats
}

\author{
J. J. FRANCHINA and J. M. BILLIG \\ Virginia Polytechnic Institute and State University, Blacksburg, Virginia 24061
}

\begin{abstract}
In Experiment 1, rats received single-alternation training with $32 \%$ or $4 \%$ sucrose reward (Phase 1) followed by a shift in reward from $32 \%$ to $4 \%$, and vice versa (Phase 2). In Phase 1, high reward facilitated alternation performance over low reward. In Phase 2, performance on rewarded trials increased as reward increased but was unchanged as reward decreased. Performance on nonrewarded trials showed negligible effects of shifts in reward. In Experiment 2, rats received goalbox placements with $32 \%$ or $4 \%$ sucrose alternated with nonreward in Phase 1; and in Phase 2, they received alternation runway training with the same or the opposite reward from that of placements. Performance on rewarded trials was faster, the higher the reward in runway training; performance on nonrewarded trials was slower, the higher the reward in placements. In Experiment 3, Phase 1 provided placements with $64 \%$, $32 \%, 16 \%$, or $4 \%$ sucrose or dry mash alternated with nonreward; Phase 2 provided alternation runway training with dry mash reward. Alternation prerformance developed more rapidly, the higher the sucrose concentration in placements. Only $64 \%$ sucrose produced performance superior to that for dry-mash placements.
\end{abstract}

Several studies have reported that, in singlealternation (SA) training with either sucrose solutions (Franchina \& Sparling, 1973) or food pellets (Campbell, Crumbaugh, Rhodus, \& Knouse, 1971; Gonzalez, Bainbridge, \& Bitterman, 1966) as reward, the larger the reward, the faster the development of alternation behavior. Specifically, these studies indicated that the larger the reward, the slower the response was on the immediately following nonrewarded trial; but reward magnitude negligibly affected responding on rewarded trials.

According to sequential theory (Capaldi, 1966, $1967,1971)$, amount of reward may influence alternation performance by (1) affecting the strength of conditioning of instrumental behavior to the stimulus aftereffects of the immediately preceding nonrewarded trial, (2) providing stimuli whose distinctive aftereffects differ in their effectiveness in signaling nonreward on the next trial, or (3) affecting the degree of contrast between reward and nonreward as discriminable events in alternation training.

Unfortunately, the comparatively sparse amount of data on the effects of reward size in SA training curtails conclusions about the relative influence of the three alternatives. Further, in the few available studies, reward occurred under instrumental training procedures, a condition which makes any (or all)

Experiments 1 and 2 were reported at the Psychonomic Society meeting in St. Louis, November 1973. Thanks are due to W. B. Pavlik for his thoughtful critique of this manuscript. Requests for reprints should be addressed to J. J. Franchina, Department of Psychology, Virginia Polytechnic Institute and State University, Blacksburg, Virginia 24061. of the alternatives seem feasible. For example, the finding of reliable effects of reward size on performance on nonrewarded trials (e.g., Campbell et al., 1971; Franchina \& Sparling, 1973; Gonzalez et al., 1966) suggests the influence of the signaling function of reward stimulus aftereffects, but this finding may also reflect a relative contrast between reward size and the immediately subsequent nonreward event. The apparent lack of reward size effects on performance on rewarded trials (e.g., Campbell et al., 1971) suggests a (suprisingly) negligible influence of reward magnitude on the strength of instrumental conditioning; but then, again, this finding may constitute a ceiling effect in rewarded responding. The purpose of the present experiments was to provide further information about the effects of amount of reward on the development of alternation performance.

\section{EXPERIMENT 1}

The purpose of this experiment was to replicate the earlier results of Franchina and Sparling (1973) and to provide more information about reward size effects in instrumental training under SA. Thus, Experiment 1 studied the effects of $32 \%$ and $4 \%$ sucrose reward on the establishment of SA runway behavior and the effects of a shift between these reward values (holding nonreward constant) on the maintenance of SA performance. The use of instrumental training procedures throughout this study admittedly obscured a clear-cut evaluation of the relative influence of the various aspects of reward (Capaldi, 1966, 1971). However, the results of the 
shift in reward size (32\% to $4 \%$ and $4 \%$ to $32 \%$ ) could provide data on the signaling function of the stimulus aftereffects of reward. From Capaldi's viewpoint of SA training (Capaldi, 1967), 32\% and $4 \%$ sucrose reward presumably occasion distinctive stimulus aftereffects which eventually come to signal responding on the immediately following nonrewarded trial. A shift in reward size should alter the aftereffects which had previously signaled responding; and performance on nonrewarded trials of postshift should show the effects (maybe disruptive) of this alteration.

\section{General Method}

Apparatus, subjects (rats), and general procedure were the same across experiments.

Apparatus. The apparatus was a straight alleyway $(146.5 \mathrm{~cm}$ long, $12.8 \mathrm{~cm}$ wide, and $10.9 \mathrm{~cm}$ high), constructed of Plexiglas (.64 cm thick) and divided by guillotine doors into a startbox, $32.1 \mathrm{~cm}$ long, a runway, $86.0 \mathrm{~cm}$ long, and a goalbox, $27.9 \mathrm{~cm}$ long. The walls of each alley section were painted flat black; the top of each section was a piece of clear Plexiglas, $.64 \mathrm{~cm}$ thick. The floor of the start and goal sections was Masonite; the floor of the runway was wire mesh. A barrier, $3.8 \mathrm{~cm}$ high, $12.8 \mathrm{~cm}$ wide, and $.16 \mathrm{~cm}$ thick, was placed in the goalbox, $6.4 \mathrm{~cm}$ in front of the rear wall. A glass caster, $3.8 \mathrm{~cm}$ in diameter and $2.6 \mathrm{~cm}$ deep, served as a goal cup and was placed behind the barrier.

Instrumental performance was measured to the nearest $.01 \mathrm{sec}$ by a timer in circuit with a photoelectric relay. The photo-cell source and receptor were recessed behind apertures $1.5 \mathrm{~cm}$ in diameter) opposite each other in the side walls of the goalbox and $3.8 \mathrm{~cm}$ in front of the barrier. Raising the startbox door activated the timer; interruption of the photobeam, $103.1 \mathrm{~cm}$ away, stopped the timer.

Subjects. The subjects were experimentally naive, male, hooded rats, 110-120 days old, from the local departmental colony. Throughout each experiment, each rat was housed individually on a continuous light cycle and was fed $10 \mathrm{~g}$ of dry ground chow daily in the home cage, $15-20 \mathrm{~min}$ after experimental treatments. Water was always available ad lib unless otherwise specified.

Procedures. Each study began with 7 days of habituation procedures followed by two experimental phases. Phase 1 was always 21 days long; Phase 2 was 10 days long in Experiment 1 and 15 days long in Experiments 2 and 3.

On Habituation Days 1-7, each rat was completely deprived of fluids except for a daily 15 -min exposure to $10 \mathrm{cc}$ of a sucrose solution delivered in a glass caster $(10.0 \mathrm{~cm}$ in diameter and $5.1 \mathrm{~cm}$ deep) in the home cage. For each rat, the concentration of sucrose was the same as that later received on rewarded trials in Phase 1. On Habituation Days 6 and 7, each rat explored the apparatus, $5 \mathrm{~min}$ on Day 6 and $3 \mathrm{~min}$ on Day 7. On the day on which Phase 1 started (Day 8 ), sucrose deliveries to the home cage ended. Plain tap water was restored ad lib to each cage from then onward.

In Experiment 1, 40 rats were randomly assigned to experimental conditions and received two phases of runway training under alternating reward and nonreward. In Phase 1, half of the rats $(\mathrm{n}=20)$ received a $32 \%$ sucrose concentration on rewarded trials; the other half received a $4 \%$ concentration. In Phase 2 , half of the rats from each Phase 1 condition $(n=10)$ were rewarded with the opposite sucrose concentration from that of Phase 1 (i.e., 32/4 and 4/32 groups). The remaining rats were rewarded with the same concentration as that previously received in Phase 1 (i.e., $32 / 32$ and $4 / 4$ groups, $n=10$ each).

Each rat received 10 alternation training trials per day throughout Phases 1 and 2 except for the first 2 days of Phase 1 when
4 and 6 trials, respectively, were administered. Training procedures were essentially those of Franchina and Sparling (1973). On rewarded trials, the rat was confined in the goalbox for $20 \mathrm{sec}$ with $5 \mathrm{cc}$ of sucrose in a goal cup. On nonrewarded trials, goalbox confinement was $20 \mathrm{sec}$ and a dry goal cup was present. This nonreward condition was held constant throughout both training phases. After a confinement period ended, the rat was removed from the goalbox and was placed into an unpainted wooden holding box $(38 \times 17.8 \times 22.9 \mathrm{~cm})$ for the intertrial interval of $20 \mathrm{sec}$. Every $48 \mathrm{~h}$, new sucrose concentrations were mixed (by weight), using commercial-grade granulated sugar and tap water. The measure of performance was total running time converted into logarithms (Franchina \& Sparling, 1973).

\section{Results}

Phase 1. Figure 1 shows that alternation performance occurred under each sucrose condition. However, alternation responding developed earlier and attained a larger magnitude, in terms of the difference in performance between nonreinforced $(\mathrm{N})$ and reinforced $(\mathrm{R})$ trials, under $32 \%$ sucrose (32/32 and $32 / 4$ groups) than under $4 \%$ sucrose (4/4 and 4/32 groups). Differences in instrumental responding between $32 \%$ and $4 \%$ conditions appeared earlier on $\mathbf{R}$ trials than on $\mathbf{N}$ trials; and, by the end of Phase 1, the $32 \%$ groups were running more rapidly on $\mathbf{R}$ trials and more slowly on $\mathbf{N}$ trials than were the $4 \%$ groups.

The results of Phase 1 were evaluated by an analysis of variance, the main factors being Phase 1 Sucrose Concentration, Phase 2 Sucrose Concentration, Trial Blocks, and N/R trials. Each analysis included "Phase 2 Sucrose Concentration" as a dummy factor to assess the groups' comparability on this variable prior to Phase 2. (No reliable effects involving this factor were obtained.)

Analysis of variance over all the data of Figure 1 yielded a reliable triple interaction, Phase 1 Sucrose Concentration by $N / R$ by Trial Blocks $[F(19,684)$ $=7.04, p<.001]$. Analysis of variance of the data of each sucrose condition separately yielded a reliable interaction, $N / R$ by Trial Blocks, in each case $[32 \%$ condition, $\mathrm{F}(19,342)=14.25, \mathrm{p}<.001 ; 4 \%$ condition, $F(19,342)=2.69, p<.01]$. The results of these three analyses together indicated that the alternation responding developed reliably for each sucrose condition; but more important, the $32 \%$ and $4 \%$ conditions differed from each other in the respective rates of alternation learning they generated. Further comparisons ( $t$ tests) between $N$ and $R$ performance on each trial block for $32 \%$ and $4 \%$ conditions separately showed that evidence of alternation performance (a reliable N-R difference) first occurred on Trial Block 10 for the $32 \%$ condition and on Trial Block 18 for the $4 \%$ condition. Comparisons between the $32 \%$ and $4 \%$ conditions by analysis of variance of R-trial and $\mathrm{N}$-trial performances separately yielded a reliable interaction of Phase 1 Sucrose Concentration by Trial Blocks in 


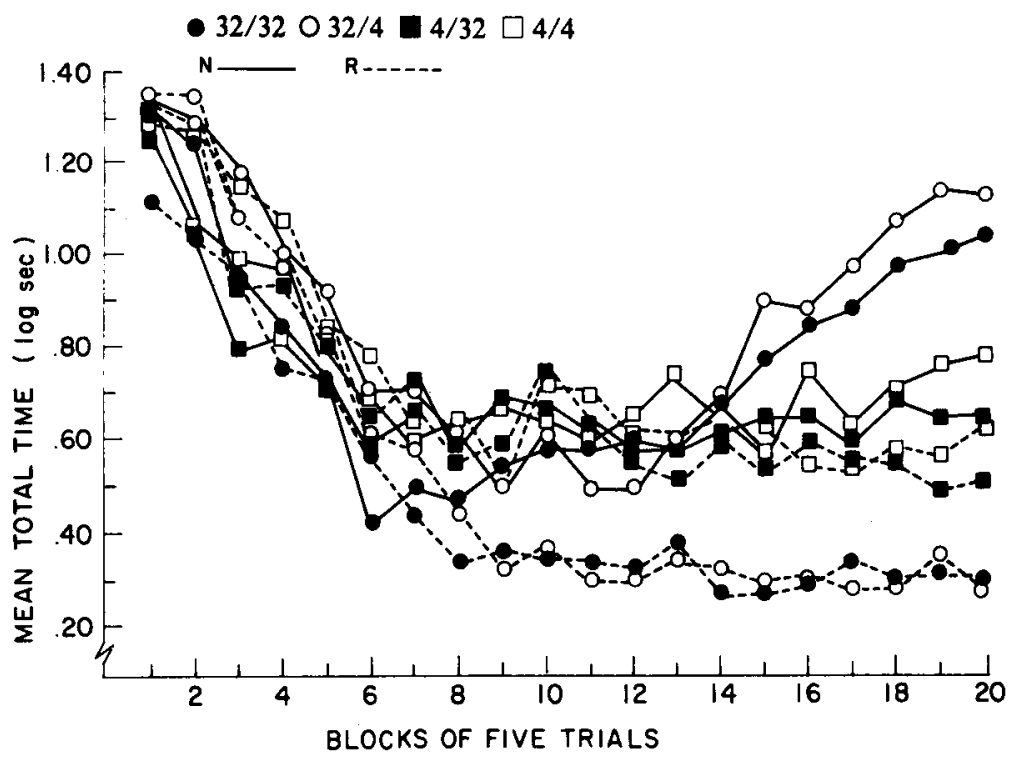

Figure 1. Mean total time in blocks of five reward trials and five nonreward trials for groups trained with $32 \%$ (circles) or $4 \%$ (squares) sucrose reward in Phase 1 of Experiment 1.

each case $(p<.01)$. This finding indicated that reward size differentially affected responding on both $\mathbf{R}$ and $\mathrm{N}$ trials; as Figure 1 shows, the difference between $32 \%$ and $4 \%$ conditions developed earlier on $\mathrm{R}$ trials than it did on $\mathrm{N}$ trials.

Terminal performance in Phase 1 was evaluated with analysis of variance over all the data of Trial Blocks 18-20. The interaction, Phase 1 Sucrose Concentration by $N / R$, was highly reliable $(F=$ 29.43), indicating, together with Figure 1, that the difference between $\mathrm{R}$ - and $\mathrm{N}$-trial performance was larger for the $32 \%$ condition than for the $4 \%$ condition. The N-R difference was reliable for each sucrose condition, however. The Trial Blocks factor was not reliable $(F=.77, p>.05)$, nor did it enter into any reliable interaction, suggesting that alternation performance was asymptotic at the end of Phase 1.

Phase 2. Figure 2 shows that alternation performance by Groups $32 / 32$ and $4 / 4$ remained relatively stable throughout Phase 2 .

Trial Blocks 1 and 2 of $\mathrm{N}$ trials indicate that following a reduction in sucrose reward, Group 32/4 showed a decrease in response times to the level of low-reward controls, Group 4/4, and then showed an increase in response times as $\mathrm{N}$-trial performance resumed a level similar to that of high-reward controls, Group 32/32. Groups 32/4 and 32/32 performed similarly to each other on $N$ trials from Trial Block 2 onward. Reward reduction produced negligible effects on performance on $R$ trials; Group $32 / 4$ generally performed similarly to Group 32/32.

Following an increase in sucrose reward, the
N-trial performance of Group 4/32 gradually approached the level of Group 32/32 but continued to appear similar to that of Group 4/4 through most of Phase 2. The increase in reward size facilitated responding on $\mathbf{R}$ trials; the performance of Group 4/32 rapidly became similar to that of Group $32 / 32$ within the first two trial blocks of Phase 2.

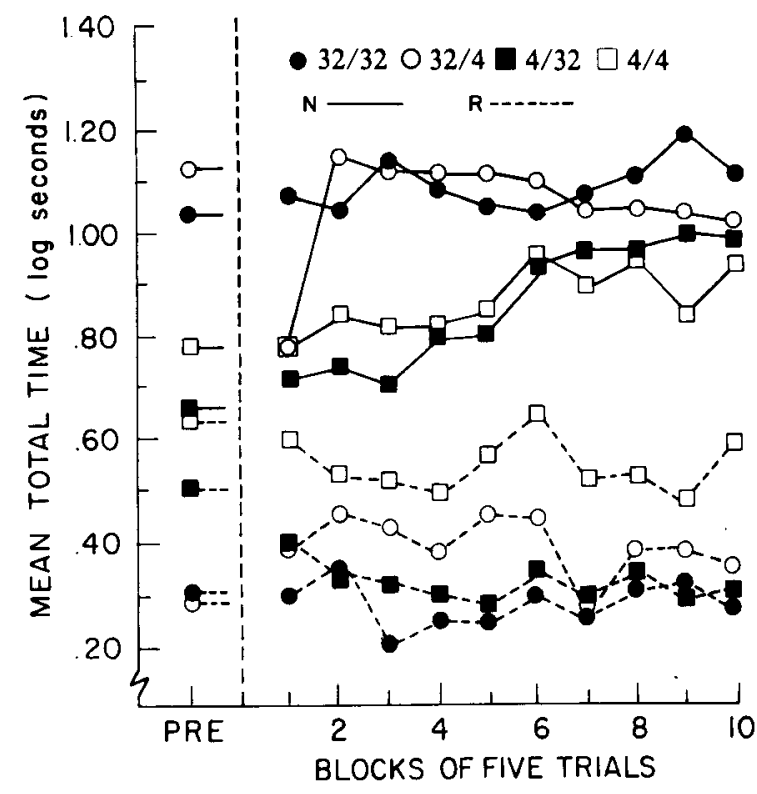

Figure 2. Mean total time in blocks of five reward trials and five nonreward trials for the last trial block (PRE) of Phase 1 and all trial blocks of Phase 2. Groups 32/32 and $4 / 4$ trained only with $32 \%$ or $4 \%$ sucrose; Groups $32 / 4$ and $4 / 32$ received a shift from 32\% to 4\% sucrose, or vice versa, from Phase 1 to Phase 2. 
Analysis of variance over all the data of Phase 2 yielded a reliable interaction of Phase 1 Sucrose Concentration by Phase 2 Sucrose Concentration by $N / R$ by Trial Blocks $[F(9,324)=2.10, p<.05]$. Analysis of variance over all the data for $R$ trials and for $\mathbf{N}$ trials separately showed that on $\mathbf{N}$ trials only the factor of Phase 1 Sucrose Concentration was reliable $[F(1,36)=8.03, p<.01]$. The absence of a reliable interaction involving Phase 2 Sucrose Concentration or Trial Blocks in this analysis of $\mathrm{N}$-trial data seemed surprising because of the striking effect of reward reduction on performance on Trial Blocks 1 and 2. Evaluation (t tests) of Trial Block 1 performance revealed that Group $32 / 4$ differed reliably from Group 32/32 [t(18) $=4.75, \mathrm{p}<.001]$ but not from Group 4/4 [t(18) $=.27]$. On Trial Block 2, Group 32/4 differed reliably from Group 4/4 $[\mathrm{t}(18)=4.20, \mathrm{p}<.001]$ but not from Group 32/32 $[\mathrm{t}(18)=.16]$. Thus, despite being reliable when considered separately, the results of Trial Blocks 1 and 2 did not generalize to produce a reliable interaction in the overall analysis. Analysis of variance of all the data for $\mathbf{R}$ trials revealed reliable effects for the interactions of Phase 1 Sucrose Concentration by Phase 2 Sucrose Concentration and Phase 1 Sucrose Concentration by Phase 2 Concentration by Trial Blocks $[F=9.02$ and 2.17, df $=1 / 36$ and $9 / 324$, $\mathrm{p}<.01$ and $<.05$ ]. Subsequent analysis of variance showed that Groups 4/32 and 32/4 differed reliably from Group $4 / 4(p<.05)$ but not from Group $32 / 32$. Finally, an analysis of variance over the data for each group separately showed that for Groups $32 / 32,32 / 4$, and $4 / 4$ only the $N / R$ factor was reliable $(F=72.69,54.59$, and 14.11$)$. Results for Group 4/32 showed a reliable interaction of $N / R$ by Trial Blocks $[F(9,81)=4.44, p<.01]$, suggesting that alternation performance continued to develop for this group in Phase 2. This suggestion was not readily apparent from Figure 2 but presumably reflected the greater change in performance on $\mathrm{N}$ trials than on $R$ trials for Group 4/32.

\section{Discussion}

Phase 1 performance showed that the higher the sucrose reward, the earlier and the more pronounced the development of alternation responding. During SA training, reliable effects of reward size occurred on $\mathbf{R}$ trials before they occurred on $\mathbf{N}$ trials. From the viewpoint of Capaldi's $(1966,1967)$ theory, this order of effects suggests that the influence of amount of reward on the conditioning of the instrumental response antedated the influence of amount of reward in providing signals for nonreward. It was possible that in SA training the decremental effects of nonreward on instrumental performance occur only after responding has been somewhat established under reward conditions. Thus, the later appear- ance of reward size effects on $\mathrm{N}$ trials in this study was a finding particular to the SA procedures. On the other hand, the $\mathrm{N}$-trial data suggest that the stimulus aftereffects of $32 \%$ and $4 \%$ sucrose reward may have initially been inadequate for signaling nonreward and became increasingly effective only with repeated alternation trials. Perhaps the stimulation provided by the sucrose rewards dissipated rapidly because the sucrose solutions dissolved in the rat's mouth. As a result, the stimulus aftereffects of the sucrose rewards were not very persistent or easily discriminable from the aftereffects of nonreward (Likely, Little, \& Mackintosh, 1971). Conversely, the stimulus traces of sucrose reward may have persisted strongly to the next trial (nonreward) to facilitate performance. Thus, the response-enhancing effects of this source of stimulation may have counteracted the decremental effects of nonreward on $\mathrm{N}$ trials (Burns, 1976).

In Phase 2, N-trial performance was directly related to the amount of reward received in Phase 1; shifts in reward magnitude on $\mathbf{R}$ trials negligibly affected N-trial results. According to Capaldi (1967), a shift in the amount of reward should alter the stimulus aftereffects which had previously signaled responding on the trial following reward (i.e., the $\mathbf{N}$ trial); and an attendant change in performance should occur. In this experiment, Groups 32/4 and $4 / 32$ presumably experienced a change in the stimulus aftereffects of reward at the start of Phase 2, but the most noticeable result was only a rather transient acceleration of $\mathrm{N}$-trial performance for Group 32/4 on Trial Block 1. On Trial Block 2, $\mathrm{N}$-trial performance by Group 32/4 returned to the level of $32 / 32$ controls, where it remained thereafter. Further, for Group 4/32, N-trial performance remained highly similar to that of $4 / 4$ controls throughout Phase 2. These results imply the operation of factors other than those related to changes in reward stimulus aftereffects.

For example, shifts in sucrose rewards may have altered the stimulus aftereffects which were peculiar to specific levels of reward; but the alternation sequence of $\mathrm{R}$ and $\mathrm{N}$ trials, and presumably their stimulus aftereffects, continued throughout training. As a result, the basis for alternation responding remained intact and $\mathrm{N}$-trial performance suffered minimal disruption. On the other hand, stimulus generalization may have rapidly occurred between the stimulus aftereffects of pre- and postshift sucrose rewards for the $32 / 4$ and $4 / 32$ groups. If so, then responding, signaled previously by the aftereffects of one reward level, may have transferred readily to the aftereffects of the other reward level.

In Phase 2, R-trial performance presumably reflected the effects of amount of reward on the 
conditioning of instrumental behavior to the stimulus aftereffects of the immediately preceding nonreward (Capaldi, 1967). Following an increase in sucrose reward, the R-trial performance of Group $4 / 32$ adjusted to the level of Group 32/32, presumably because the increase in reward increased the conditioning of instrumental behavior to nonreward aftereffects. Following a decrease in sucrose reward, R-trial performance by Group 32/4 remained highly similar to that of Group 32/32, presumably because the stimulus aftereffects of nonreward, which had signaled R-trial performance, continued to be available to evoke responding and because the response asymptote for $32 \%$ sucrose reward superceded that for $4 \%$ sucrose reward.

\section{EXPERIMENT 2}

Experiment 1 provided information on the effects of reward size on alternation performance but was relatively equivocal on how reward size was influential. The manipulation of amount of reward under conditions which permitted performance of the instrumental response precluded the making of clearcut conclusions about the separate effects of the various aspects of reward size (i.e., instrumental conditioning, signaling, and contrast). However, the influence of amount of reward in the conditioning of the instrumental response on $\mathbf{R}$ trials seemed an especially prominent result which developed early in SA training and possibly could have mediated the effects of the other aspects of reward. Thus, the purpose of Experiment 2 was to study the effects of amount of reward on the development of alternation performance when the instrumental conditioning aspect of reward size was precluded. Franchina, Sparling, and Chlipala (1971) proposed that signaling and instrumental conditioning aspects of reward/nonreward might be separated from each other by the use of pretraining goalbox placements which precluded (or minimized) performance of the full instrumental response of traversing the alleyway. In their study, goalbox placements under alternation and random schedules of reward/nonreward, respectively, facilitated and impaired the subsequent development of alternation performance relative to nonplaced controls. Experiment 2 followed the logic of that study. Specifically, rats received goalbox placements with either $32 \%$ or $4 \%$ sucrose reward in alternation with nonreward prior to instrumental training under SA procedures. Placement procedures prevented the performance of the full instrumental response and thereby precluded (or minimized) the influence of reward size on the instrumental conditioning of runway behavior. However, placements did permit the influence of signaling and/or contrast aspects of reward size. If signaling and/or contrast aspects of reward size in placements related directly to amount of reward, then the higher the sucrose reward in placements, the slower the response on $\mathrm{N}$ trials of subsequent SA training and the earlier the development of alternation responding.

\section{Method}

Subjects. Sixty male, hooded rats were used.

Design and Procedures. Each rat received 7 days of habituation, 21 days of goalbox placements in Phase 1 , and 15 days of SA training in Phase 2. Habituation procedures were those from Experiment 1.

In Phase 1, 20 rats received goalbox placements with $32 \%$ sucrose reward in alternation with nonreward; 20 other rats received placements with $4 \%$ sucrose reward in alternation with nonreward. In Phase 2, all rats received SA training in the runway. Half of the rats from each sucrose reward condition of Phase $1(n=10)$ received SA training with the same reward level as that received in placements (i.e., $32 / 32$ and $4 / 4$ groups); the other half of the rats received SA training with the sucrose reward opposite to that received in placements (i.e., $32 / 4$ and 4/32 groups).

According to this design, placements could affect SA training either because placements provided an alternation sequence of reward and nonreward or because placements simply provided exposures to reward and nonreward events prior to runway training. To evaluate these possibilities, two additional control groups, $32 \mathrm{R}$ and $4 \mathbf{R}(\mathbf{n}=10)$, received goalbox placements under a random schedule of reward $(32 \%$ or $4 \%$ sucrose) and nonreward. In Phase 2 , Groups $32 \mathrm{R}$ and $4 \mathrm{R}$ received SA training with the same sucrose reward as that received during random placements.

For all groups, goalbox placement procedures followed those described by Franchina et al (1971). Briefly, each rat was removed from the holding box, was placed into the goalbox, head down directly over the goal cup, and was confined for $20 \mathrm{sec}$. On reward placements, the goal cup contained $5 \mathrm{cc}$ of the appropriate sucrose solution. On nonreward placements, a dry goal cup was present. After $20 \mathrm{sec}$ of confinement, the rat was returned to the holding box for an interplacement interval of $20 \mathrm{sec}$. Each rat received 10 placements per day except on Days 1 and 2, which provided 4 and 6 placements, respectively. Alternation training began on the day after placements ended. Training-trial procedures followed those described in Experiment 1 . Each rat received 10 trials per day. The measure of performance was total running time, transformed into logarithms.

\section{Results}

Figure 3 shows that alternation responding developed for each of the SA placement groups. Group $32 / 32$ showed the earliest and the most pronounced display of alternation performance; Group 4/4 showed the latest and the smallest display of alternation behavior. Comparison of the results of Figure 3 with those of Figure 1 (Experiment 1) showed that, in Experiment 2, pretraining goalbox placement with either $32 \%$ or $4 \%$ sucrose reward facilitated the development of alternation performance. Figure 3 shows that sizable evidence for alternation behavior first occurred for Groups 32/32 and $4 / 4$ on Trial Blocks 5 and 11 , respectively. In Experiment 1, the first reliable appearance of alternation performance for the $32 \%$ and $4 \%$ sucrose 


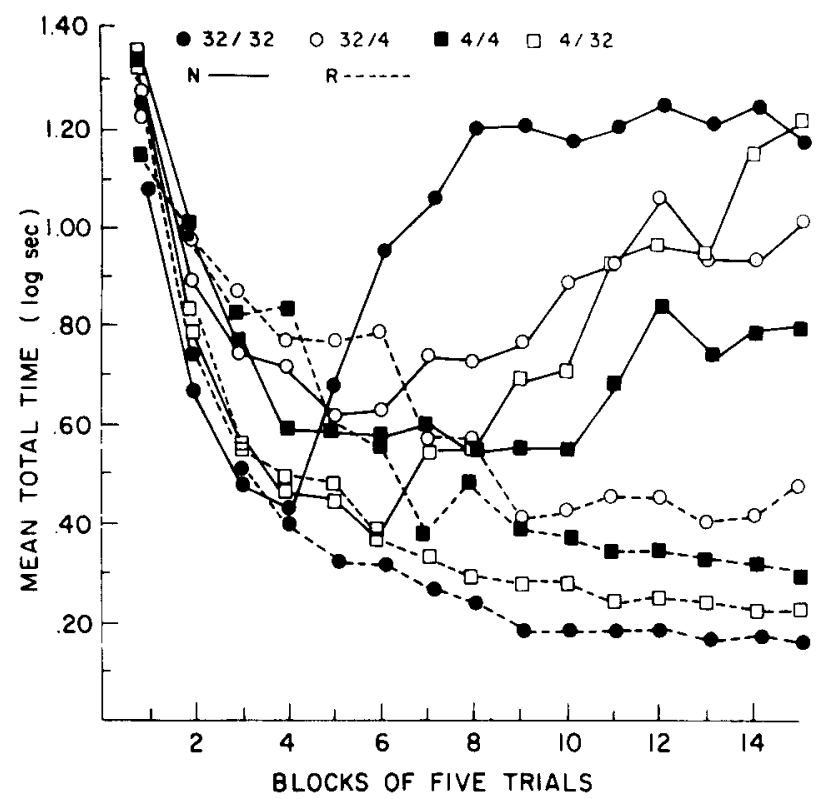

Figure 3. Mean total time in blocks of five reward trials and five nonreward trials for groups which received pretraining goalbox placements with either $32 \%$ or $4 \%$ sucrose reward and then alternation runway training either with the same sucrose concentration as that of placements (Groups $32 / 32$ and 4/4) or with the opposite concentration from that of placements (Groups 32/4 and 4/32).

reward conditions was on Trial Blocks 10 and 18 , respectively. Further, comparisons of the magnitude of alternation responding between the data of Figures 1 and 3 show that, for Groups $32 / 32$ and $4 / 4$, the differences between $N$ and $R$ trials were larger at the end of 15 trial blocks in the data of Figure 3 than they were after 20 trial blocks in the data of Figure 1 for $32 \%$ and $4 \%$ sucrose conditions. Goalbox placement procedures of Experiment 2 apparently facilitated the initial appearance and the final magnitude of alternation behavior relative to that of nonplaced groups from Experiment 1 .

Figure 3 also shows that on $\mathbf{N}$ trials instrumental responding was slower, the higher the sucrose reward in placements. With amount of reward in training held constant, Group 32/32 ran more slowly on $\mathbf{N}$ trials than did Group 4/32, and Group 32/4 ran more slowly than did Group 4/4. Conversely, on $\mathbf{R}$ trials, instrumental responding was faster, the higher the sucrose reward was in training: Groups $32 / 32$ and $4 / 32$ ran more rapidly than Groups $32 / 4$ and $4 / 4$.

The data of Figure 3 were evaluated with analysis of variance; the main factors were Placement Sucrose Concentration, Training Sucrose Concentration, Trial Blocks, and N/R trials. Analysis of variance over all the data of Figure 3 yielded a reliable interaction of Placement Sucrose Concentration by Training Sucrose Concentration by Trial Blocks by
$\mathrm{N} / \mathrm{R}[\mathrm{F}(14,504)=2.32, \mathrm{p}<.01]$. To evaluate this interaction, analysis of variance was applied to all the data for $\mathbf{N}$ trials and for $\mathbf{R}$ trials separately. For $\mathbf{N}$ trials, the interaction, Placement Sucrose Concentration by Training Sucrose Concentration by Trial Blocks, was reliable $(p<.01)$. Subsequent analysis of variance showed that over Trial Blocks 1 and 2 neither Placement nor Training Sucrose Concentration was reliable, but that over Trial Blocks 11-15 Placement Sucrose Concentration and Training Sucrose Concentration were both reliable $(p<.01)$. Analysis of variance over all the R-trial data yielded a reliable interaction of Training Sucrose Concentration by Trial Blocks $(p<.001)$ but no reliable effects involving Placement Sucrose Concentration $(F s<1)$. Subsequent analysis of variance showed that over Trial Blocks 1 and 2 neither Placement nor Training Sucrose Concentration was reliable and that over Trial Blocks 11-15 only Training Sucrose Concentration was reliable $(p<.001)$. Placement Sucrose Concentration, Trial Blocks, and each interaction (e.g., Placement by Training Sucrose Concentration) yielded $F$ values of less than 1 in the latter analysis. Finally, to identify the first reliable occurrence of alternation responding for each group, a $t$ test comparison between $\mathrm{N}$ - and $\mathrm{R}$-trial performance was made on each trial block. Reliable evidence for alternation performance first occurred on Trial Blocks 5, 7, 9, and 11 for Groups 32/32, 4/32, 32/4, and 4/4, respectively $(p<.05)$.

For purposes of graphical clarity, Figure 3 did not present the alternation performance of random placement groups, $32 \mathrm{R}$ and $4 \mathrm{R}$. Alternation responding developed reliably for Group 32R [Trial Blocks by $N / R, F(14,126)=1.95, p<.05]$ and approximated that shown in Figure 3 for Group 4/4. Reliable evidence for alternation behavior first occurred on Trial Block 12; the largest difference in mean performance between $\mathrm{N}$ - and $\mathrm{R}$-trial blocks was .30 log sec. Group 4R showed nondifferential responding between $\mathrm{N}$ and $\mathrm{R}$ trials and consistently performed at a level that was highly similar to that shown on $R$ trials by Group $4 / 4$ in Figure 3. The results of Groups $32 R$ and $4 R$ are pertinent because, when compared with the results of Groups $32 / 32$ and $4 / 4$ in Experiment 2 and with the results of (nonplaced) groups in $32 \%$ and $4 \%$ sucrose conditions in Experiment 1, Phase 1, they indicate that sheer placements with reward and nonreward were apparently inadequate to facilitate alternation performance. Relative to the results of Experiment 1, the data of Experiment 2 showed that an alternation sequence of placements facilitated and a random sequence impaired subsequent SA training. 


\section{Discussion}

The results of Experiment 2 underscored the influence of pretraining goalbox placements and the role of amount of reward in placements on subsequent SA training. Groups $32 / 32$ and $4 / 4$ received alternation placements in Experiment 2 and subsequently showed more rapid and more pronounced development of alternation responding than did groups which received only instrumental (SA) training under $32 \%$ or $4 \%$ sucrose reward in Experiment 1. Experiment 2 also showed that, with reward size held constant in training, the higher the sucrose reward in goalbox placements, the more rapid the subsequent development of alternation behavior.

In terms of specific $\mathrm{N}$ - and R-trial behavior, however, amount of reward in placements yielded reliable persisting effects only for $\mathrm{N}$-trial performance. It did not seem to affect R-trial performance, which appeared to be related directly to amount of reward in instrumental (SA) training, a finding which supported Capaldi's (1967) reinforcement viewpoint. Specifically, Capaldi (1967) proposed that the larger the reward on $R$ trials of SA training, the more strongly the instrumental response would be conditioned to the stimulus aftereffects of the immediately preceding nonreward trial.

In SA training, progressively slower responding develops on $\mathrm{N}$ trials because the immediately preceding reward event eventually comes to signal nonreward for responding on the next trial (i.e., $\mathbf{N}$ ). In Experiment 2, 32\% and 4\% sucrose reward presumably occasioned distinctive aftereffects stimuli which differed from each other in the capacity to signal subsequent nonreward. The aftereffects of $32 \%$ sucrose may have been more intense than those of $4 \%$ sucrose and, thereby, constituted a better (stronger or more efficient) signal for the upcoming event, $N$. The aftereffects of $4 \%$ sucrose reward may have been weak and relatively less discriminable from the stimulus aftereffects of nonreward, and thus ineffectually signaled upcoming N. Accordingly, N-trial performance slowed earlier for Groups $32 / 32$ and $32 / 4$ than for Group $4 / 4$, because placements with $32 \%$ sucrose provided more effective signals for upcoming nonreward than did placements with 4\% sucrose. Presumably this efficacy persisted to SA training for the $32 \%$ groups despite a change in sucrose reward for Group 32/4. Performance on $\mathrm{N}$ trials was slower for Group 32/32 than for Group $32 / 4$ because the shift in sucrose reward from placements to SA training altered the stimulus aftereffects which had signaled nonreward for Group 32/4; thus this group's performance reflected an aftereffects stimulus generalization decrement (relative to Group 32/32). For Group $4 / 32$, placements with $4 \%$ sucrose reward may have provided aftereffects stimuli which were ineffectual signals for upcoming nonreward. This experience may have persisted to SA training to affect the alacrity with which $\mathrm{N}$-trial performance slowed for Group 4/32 relative to Group 32/32. However, $\mathrm{N}$-trial performance slowed earlier for Group 4/32 than for Group 4/4. The basis for this effect may have been either that the change in sucrose reward from placements to training yielded a generalization decrement which attenuated the deleterious influence of prior goalbox placements for Group 4/32, or the presentation of $32 \%$ sucrose reward in SA training for Group 4/32 provided stimulus aftereffects which gradually overcame the inadequacies of prior placements.

Further evidence for the influential role of the signaling aspect of reward size was the finding that both $\mathrm{N}$-trial performance and the rate at which alternation behavior developed showed similar effects of amount of reward in placements; the larger the amount of reward in placements, the earlier $\mathrm{N}$-trial performance slowed down and the more rapid the development of alternation responding. Compare the results for Groups $32 / 32$ vs. $32 / 4,32 / 32$ vs. $4 / 32$, and $32 / 4$ vs. $4 / 4$. These effects apparently were not attributable to response generalization based on R-trial performance differences. Group $32 / 32$ was reliably slower than Groups $32 / 4$ and $4 / 32$ on $N$ trials; but on $R$ trials, Group $32 / 32$ ran reliably faster than Group $32 / 4$ and ran similarly to Group $4 / 32$. Groups $32 / 4$ and $4 / 32$ were reliably slower than Group $4 / 4$ on $N$ trials, but on $R$ trials Group 4/32 ran faster than Group $4 / 4$ and Group 32/4 ran similarly to Group 4/4.

\section{EXPERIMENT 3}

Experiment 2 showed that pretraining goalbox placements with high or low sucrose reward reliably facilitated subsequent SA training relative to nonplaced groups from Experiment 1. The transfer of placement experience to instrumental training was due, in part, to the effectiveness of the signaling properties of the magnitudes of reward used in placements and, in part, to the occurrence of aftereffects stimulus generalization which was fostered by the use of sucrose reward in placements and SA training.

Experiment 3 investigated the effects of placement and amount of reward on the subsequent development of alternation behavior when the type of reward differed between placements and training. Rats received pretraining goalbox placements with $64 \%, 32 \%, 16 \%$, or $4 \%$ sucrose reward in alternation with nonreward, and then received SA training with dry mash reward. The use of different types of reward between placements and training 
(sucrose vs. dry food) should attenuate any transfer based simply on the physical similarity between reward events. However, it is uncertain whether the results will show zero transfer effects relative to nonplaced controls, transfer effects which are the same for all levels of sucrose, or transfer effects which relate directly to the amount of sucrose reward in placements. The last alternative may be possible, considering the results of $\mathrm{N}$ trials in Experiment 2. If the influence of placement amount of reward persists to SA training in Experiment 3 despite the change in type of reward, then $\mathrm{N}$-trial performance should be slower, the higher the sucrose reward in placements.

\section{Method}

Forty-five male hooded rats were used in the main experiment. Each rat received habituation, placement (Phase 1), and SA training (Phase 2) procedures exactly as described in Experiment 2. In Phase 1 , the rats received goalbox placements with $64 \%$, $32 \%, 16 \%$, or $4 \%$ sucrose reward or dry mash (DM) reward in alternation with nonreward ( $n=9$ rats per group). In Phase 2, all rats received SA training with dry mash reward for 15 days. In SA training, $R$ trials provided 20 -sec access to dry mash in a goal cup; $\mathbf{N}$ trials provided $20 \mathrm{sec}$ of confinement in the goalbox with an empty goal cup. To evaluate the development of alternation performance under dry mash reward in the absence of pretraining goalbox placements, an additional group of rats $(n=9)$, DMC, received only handling procedures which were comparable to those experienced by the goalbox placement groups prior to SA. Further, in Experiment 2, the alternation performance of the random placement groups, $32 R$ and $4 R$, indicated that sheer exposures to reward and nonreward in pretraining were not in themselves sufficient to enhance SA training. (In fact, random placements seemed to impair SA training.) To evaluate the effects, of pretraining exposures to sucrose reward and nonreward on alternation performance under dry mash, two additional groups, 64R and $16 \mathrm{R}(\mathrm{n}=9 \mathrm{each})$, received goalbox placements under a random schedule of either $64 \%$ or $16 \%$ sucrose reward and nonreward prior to SA training with dry mash. In this experiment, the measure of performance was total running time, transformed into logarithms.

\section{Results}

Figure 4 shows that alternation performance occurred for each of the alternaton placement groups. Most striking was the finding that the $64 \%$ sucrose group showed the most rapid and generally the most pronounced development of alternation behavior. By Trial Block 4, Group 64\% showed a sizable difference between $\mathrm{N}$ - and R-trial performance. Groups $32 \%, 16 \%$, and $4 \%$ sucrose and Group DM were similar to each other in the development of alternation performance; each group showed sizable differences between $\mathrm{N}$ - and R-trial performance by Trial Block 8 .

Figure 4 omitted the data of Group DMC for purposes of graphical clarity and because the performance of DMC was highly similar to that of Group DM except for the initial appearance of alternation behavior. For Group DMC, reliable alternation responding first appeared on Trial Block $10(p<.001)$ Groups DMC and DM showed highly similar magnitudes of alternation responding over Trial Blocks 13-15 (Groups $\mathrm{F}<1$ ) and comparable levels of terminal performance on $\mathrm{N}$ trials and on $\mathrm{R}$ trials (ps $>.05$ ).

Analysis of variance evaluated all the data of Figure 4, including the data of Group DMC. The main factors were Placement Conditions, Trial Blocks, and N/R trials. This analysis yielded reliable effects for Placement Conditions and for the interaction of Placement Condition by Trial Blocks by $\mathrm{N} / \mathrm{R}(\mathrm{F}=3.37$ and 1.86 , df $=5 / 54$ and $70 / 756$, $\mathrm{p}<.05$ and $<.01$, respectively). To clarify this interaction, analysis of variance was applied to all the data for $\mathbf{N}$ trials and for $\mathbf{R}$ trials separately. For $\mathrm{N}$ trials, results showed that the interaction of Placement Conditions by Trial Blocks was reliable $(p<.01)$, indicating that placement conditions yielded differential rates of response change over blocks of $\mathrm{N}$ trials. Scheffé comparisons showed that Groups $64 \%$ and DMC differed reliably from each other and from each of the other groups (ps $<.05$ ). No other group differences were reliable. Analysis of the R-trial data showed that the effect, Trial Blocks, alone was reliable $(p<.001)$. No reliable effects were obtained for Placement Condition or for any interaction involving Placement Condition (ps $>.05$ ). Finally, to identify the first occurrence of reliable alternation responding for each group, t-test comparisons between $\mathrm{N}$ - and R-trial performance were made on each trial block. Reliable alternation responding occurred for the first time on Trial Blocks 3, 6, 7, 8, 9, and 10 for Groups

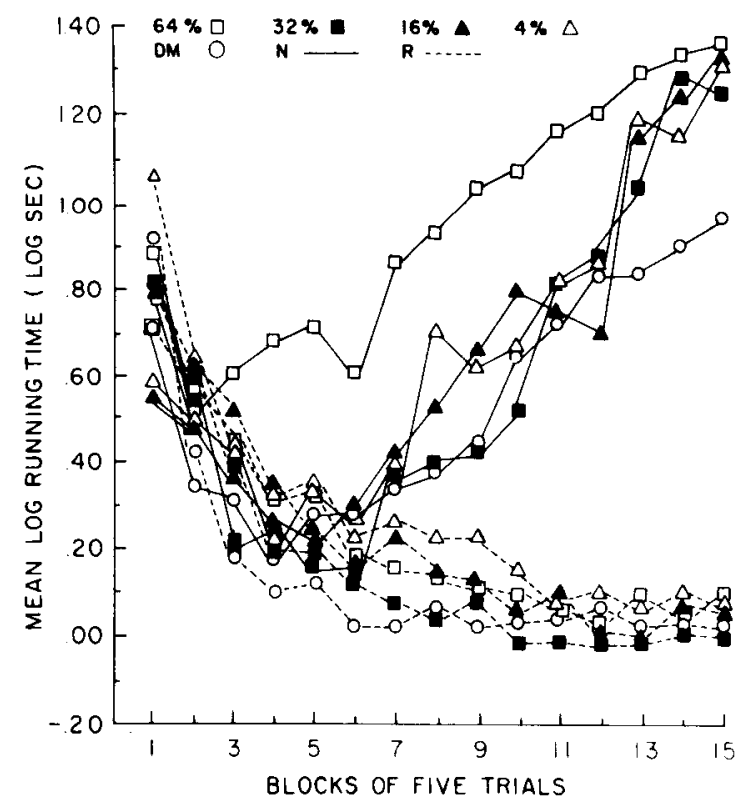

Figure 4. Mean total time in blocks of five reward trials and five nonreward trials for groups which received pretraining goalbox placements with $64 \%, 32 \%, 16 \%$, or $4 \%$ sucrose reward or with dry mash (DM) reward and then alternation runway training with dry mash reward. 
$64 \%$ sucrose, DM, $32 \%, 16 \%$, and $4 \%$ sucrose, and DMC, respectively.

The random placement groups, 64R and 16R, showed reliable alternation responding under dry mash ( $\mathrm{ps}<.05)$. The first reliable occurrence of alternation behavior was Trial Block 11 for Group 64R and Trial Block 12 for Group 16R. The results of these groups foster the same conclusion as did the data for Groups $32 \mathrm{R}$ and $4 \mathrm{R}$ in Experiment 2, namely, exposures to reward and nonreward in pretraining placements were not in themselves sufficient to facilitate subsequent SA training. A random sequence of goalbox placements seemingly impaired subsequent SA training in both experiments.

\section{Discussion}

Experiment 3 showed that, despite a change in type of reward from placements to SA training, the amount of sucrose reward in placements directly affected the rate of development and in general the magnitude of alternation behavior. For Groups $64 \%, 32 \%, 16 \%$, and $4 \%$, the higher the reward in placements, the earlier in SA training reliable alterntion behavior appeared and generally the slower the instrumental response was on $\mathbf{N}$ trials. Not surprisingly, the level of sucrose reward in placements did not affect R-trial performance. This finding was consistent with conclusions from the R-trial data of Experiment 2, namely, R-trial performance in Experiment 2 related directly to amount of reward during SA training and presumably reflected the influence of reward size on the conditioning of the instrumental response to the immediately preceding nonreward's aftereffects. In Experiment 3, all groups received the same reward (dry mash) following instrumental responding on $\mathrm{R}$ trials. Instrumental conditioning was thus held constant and performance should not have differed reliably across placement groups.

The provocative finding of this experiment was that despite the qualitative difference between the reward used in placements and that used in SA training, the effects of placement amount of reward transferred to N-trial performance. Sucrose in solution is a liquid reinforcer; dry mash is a solid food reinforcer. Consequently, their respective stimulus aftereffects should have differed from each other and on the basis of stimulus generalization decrement negligible transfer effects could have resulted.

Two explanations of the present evidence for transfer seem possible. The first explanation is essentially similar to that offered earlier for the results of Experiment 2. The concentrations of the sucrose reward in placements may have provided different intensities of gustatory stimulation, $64 \%$ sucrose providing the most intense stimulation, $32 \%$ sucrose, the next most intense, and so on; and the intensity of taste stimulation may have regulated the adequacy with which the stimulus aftereffects of sucrose reward in placements signaled upcoming nonreward. Thus the stimulus aftereffects of $64 \%$ sucrose reward provided better signals for upcoming nonreward than did the stimulus aftereffects of $32 \%$ sucrose because of the stronger taste of $64 \%$ sucrose. The stimulus aftereffects of $32 \%$ sucrose provided better signals for nonreward than did those of $16 \%$ sucrose, and so on for further comparisons of pairs of sucrose groups. This experience may then have transferred to SA training because the same sequence of reward-nonreward occurred in placements and in training and because dry mash reward in training evoked the memory of sucrose reward from placements. In placements and in SA training, Groups $64 \%, 32 \%, 16 \%$, and $4 \%$ received an alternation sequence of reward and nonreward. If dry mash and sucrose were goal events of the same general class, reward, as distinct from the other general class of goal events, nonreward (Bower \& Kaufman, 1963), then the alternation sequence of reward-nonreward in training may have reproduced the same pattern of generic aftereffects of reward qua reward (vs. nonreward) as that from placements. Accordingly, for each sucrose group, receipt of dry mash reward in SA training may have evoked the memory of the previous sucrose reward; and the effectiveness with which that (sucrose) reward's aftereffects signaled nonreward may have transferred to influence $\mathrm{N}$-trial performance. This interpretation leans heavily on the development of the signaling aspect of reward size in pretraining placements and presumes that transfer to SA training occurred on the basis of factors other than those related to sheer physical similarity between sucrose and dry mash rewards.

The second explanation for the present evidence of transfer is that the degree of discrepancy between the amount of reward and nonreward in placements influenced the development of inhibition to nonreward (Capaldi, 1967; Leonard, 1969). The higher the sucrose reward was in placement, the greater the contrast between reward and nonreward and the more inhibition was likely to develop on nonrewarded placements. Thus, more inhibition accrued to nonreward in placements for the $64 \%$ group than for the $32 \%$ group, etc. In subsequent SA training, the reward was changed to dry mash, but the sequence of alternating goal events and the conditions of nonreward remained the same from placements. During instrumental training, then, the recurrence of nonreward may have reinstated the inhibition which had accrued to nonreward in pretraining placements. Thus $\mathrm{N}$-trial performance was slower for the $64 \%$ group than for the $32 \%$ group because more inhibition transferred from nonrewarded placements for the $64 \%$ group than for the $32 \%$ group. In this interpretation, the signaling aspect of reward 
during SA training is presumed to be constant across sucrose placement groups. The difference in $\mathrm{N}$-trial performance reflects contrast effects of reward size, which transferred from placements for the sucrose groups.

\section{GENERAL DISCUSSION}

These three experiments showed that amount of reward directly affects the initial appearance and the eventual magnitude of alternation behavior whether amount of reward was manipulated in instrumental (SA) training or in pretraining goalbox placements. In Experiments 1 (Phase 1) and 2, responding on $R$ trials was faster, the higher the reward; in Experiments 1 (Phase 1), 2, and 3, responding on $\mathrm{N}$ trials was slower, the higher the reward.

Among the several functions which Capaldi (1966, 1971) ascribes to reward magnitude, the present data suggest that the influence of amount of reward on the conditioning of the instrumental response may be preeminent to signaling and contrast aspects of reward. For example, in Experiment 1 (Phase 1), reliable effects of reward size on R-trial performance antedated any effects of reward size on $\mathrm{N}$-trial performance. In Phase 2 of Experiment 1, shifting from $32 \%$ to $4 \%$ sucrose reward and vice versa negligibly affected previously established alternation performance, although a shift in reward magnitude presumably altered the stimulus aftereffects and the contrast aspects of reward (Capaldi, 1966) and thereby should have produced a more substantial change in performance then occurred. Reliable effects of reward magnitude shifts did occur in Experiment 2. Here reward was shifted from one level in goalbox placements to a different level in subsequent SA training. Placement procedures precluded performance of the full instrumental response, thereby presumably curtailing the influence of amount of reward on instrumental response conditioning and allowing evidence for signaling and contrast aspects of reward to appear.

The data of Experiments 2 and 3 indicated that the signaling and contrast aspects of amount of reward might promote the development of alternation behavior relatively independently of instrumental response performance. The use of pretraining goalbox placements in these studies minimized the contribution of the instrumental conditioning aspect of reward size. However, placements did not permit a separation of the relative influences of stimulus aftereffects (signaling) and contrast aspects of reward size. The $\mathrm{N}$-trial performance in each experiment may reflect either or both of these aspects. On the other hand, the results of Groups $32 \mathrm{R}$ and $4 \mathrm{R}$ in Experiment 2 and of Groups 64R and $16 \mathrm{R}$ in Experiment 3 raise some qualifications about the adequacy of a contrast type of explanation. In both experiments, pretraining random placement procedures impaired the development of subsequent alternation performance relative to nonplaced groups in Experiments 1 and 3. Random placements provided the same number of exposures to reward and nonreward events as did alternation placements, but the sequence of $\mathbf{R}$ and $\mathrm{N}$ differed between placement procedures. Thus, the opportunity for contrast to develop between the amounts of reward and nonreward should have been the same for random as for alternation placements, while the ordering of goal events should have permitted development of a signaling capacity for the stimulus aftereffects of reward and nonreward under the alternation procedure but not under the random procedures. The results of Experiments 2 and 3 showed that alternation placements facilitated and random placements impaired subsequent SA training relative to nonplaced groups. These data indicate a strong influence of the sequence of placement events, suggesting that the signaling aspect of amount of reward may have superceded the contrast aspect.

\section{REFERENCES}

Bower, G., \& Kaufman, R. Transfer across drives of the discriminative effect of a Pavlovian conditioned stimulus. Journal of the Experimental Analysis of Behavior, 1963, 6, 445.448.

BuRns, R. A. Effects of sequences of sucrose reward magnitudes with short ITIs in rats. Animal Learning \& Behavior, 1976. 4, 473.479.

Campbell, P. E., Crumbaugh, C. M., Rhodus, D. M., \& KNouse, S. B. Magnitude of partial reward and amount of training in the rat: An hypothesis of sequential effects. Journal of Comparative and Physiological Psychology, 1971, 75 120-128.

Capaldi, E. J. Partial reinforcement: A hypothesis of sequential effects. Psychological Review, 1966, 73, 459-477.

CAPALdI, E. J. A sequential hypothesis of instrumental learning. In K. W. Spence \& J. T. Spence (Eds.), The psychology of learning and motivation (Vol. 1). New York: Academic Press, 1967.

Capaldi, E. J. Memory and learning: A sequential viewpoint. In W. K. Honig \& P. H. R. James (Eds.), Animal memory New York: Academic Press, 1971.

Franchina, J. J., \& Sparling, D. L. Effects of sucroseconcentrations on single alternation runway responding in rats. Learning and Motivation, 1973, 4, 471-479.

Franchina, J. J.. Sparling, D. L., \& Chlipala, R. Effects of patterns of goal-box placements on the subsequent acquisition of instrumental response patterning. Journal of Comparative and Physiological Psychology, 1971, 74, 84-89.

Gonzalez, R. C., Bainbridge, P., \& Bittenman, M. E. Discrete-trials lever pressing in the rat as function of pattern of reinforcement, effortfulness of response and amount of reward. Journal of Comparative and Physiological Psychology. $1966,61,110-122$.

LeONARD, D. W. Amount and sequence of reward in partial and continuous reinforcement. Journal of Comparative and Physiological Psychology, 1969, 67, 204-211.

Likely, D., Little, L., \& Mackintosh, N. J. Extinction as a function of magnitude and percentage of food or sucrose reward. Canadian Journal of Psychology Review of Canadian Psychology. 1971, 25, 130-137.

(Received for publication April 22, 1977; revision accepted February 16, 1978.) 